\title{
25 Research Square \\ Interdigital Coupled Compact FSS Reflector for UWB Antenna Gain Enhancement
}

Gobinda Sen ( $\nabla$ gobinda.dets@gmail.com )

IEM: Institute of Engineering and Management https://orcid.org/0000-0001-9211-5339

\section{Santanu Das}

Indian Institute of Engineering Science and Technology

\section{Research Article}

Keywords: UWB, Interdigital coupled, FSS reflector, Half circular disc monopole.

Posted Date: June 3rd, 2021

DOI: https://doi.org/10.21203/rs.3.rs-492229/v1

License: (9) This work is licensed under a Creative Commons Attribution 4.0 International License. Read Full License 


\section{Abstract}

A compact UWB FSS reflector is presented based on interdigital structure for gain enhancement of an UWB antenna. An equivalent circuit approach is proposed for the analysis of the FSS reflector. The reflector comprises a $6 \times 6$ array of unit cell dimension $6 \mathrm{~mm} \times 6 \mathrm{~mm}$ and which is very compact. The reflector gives a linear phase response over UWB band. A UWB monopole antenna is designed with a half circular disc structure based on microstrip technology. A maximum of $5 \mathrm{dBi}$ gain enhancement is achieved with this compact FSS reflector when placed at a distance below the antenna. The measured results closely follow the simulated ones which proves feasibility of this design.

\section{Introduction}

Over the last few years, Ultra-wideband (UWB) technology is found to have potential in impulse radio, communication systems, ground-penetrating radar (GPR) and microwave imaging [1]. The commonly used radiator for UWB antenna system is monopole antenna due to their omnidirectional radiation pattern. However, it suffers from low gain and higher back side radiation. In order to provide better signal to noise ratio (SNR), the main lobe gain is to be much higher as compared to side lobes. The use of FSS reflector is found to be prominent solution for gain enhancement of monopole antennas. FSS having band stop response with linear decaying phase over the UWB frequencies is widely used as reflector of antenna system to minimize back lobe radiation. FSS has found wide space application in radar [2], antenna array [3], and RFID [4].

Multi-layer structures are popular for obtaining UWB frequency response. The use of stack FSS layers with different frequency responses are commonly used technology for UWB reflector design [5-6]. In [6], a UWB FSS reflector based on four-layer structure improves the gain of a slot antenna over the wide band. The use of multiple layers is also enhanced the design cost and complexity and not suitable for low profile compact antenna system. Therefore, the double layer and single layer structure is gaining attention by the researcher over the years [7]. In [8], a gain enhancement of maximum $7 \mathrm{~dB}$ over UWB frequency is obtained with a dual layer FSS comprises $5 \times 13$ array of unit cell with dimension of 22.4 $\mathrm{mm} \times 6.5 \mathrm{~mm}$. Recently, metamaterial is used for the design of miniaturized FSS [9]. FSS reflectors based on single layer structure are found to have potential for gain enhancement in a low-profile compact antenna system [7, 10-11]. In [12], a stop band characteristic of FSS reflector is obtained with ring-based structure. Miniaturized FSS is designed with higher dielectric constant material but it also increases the design cost.

This paper presents a compact FSS reflector based on interdigital capacitor for gain enhancement of a UWB monopole antenna. The FSS reflector exhibits a linear phase response with band stop characteristic over UWB frequency.

The unit cell size of FSS is $6 \mathrm{~mm} \times 6 \mathrm{~mm}$, which is $0.06 \lambda \_L$ (corresponding to lowest resonant frequency) and hence is compact. A $6 \times 6$ array of the unit cell FSS is loaded to a UWB monopole antenna to achieve 
a gain enhancement of maximum $4.25 \mathrm{dBi}$ as compared to antenna without loading over the UWB range. The design and theoretical analysis of the proposed work is carried out with CST Microwave Studio. The design is also fabricated and the measured results are compared with the simulated one to validate the work.

This work is represented as follows. Section 2 discusses the design of unit cell, UWB monopole antenna, the FSS reflector loaded UWB antenna and their simulation. In Sect. 3, the prototypes of the proposed design are fabricated and measured, and the test results are compared with the simulated ones. Finally, in Sect. 4, the conclusions of the proposed work are carried out.

\section{li. Design And Results}

The design of the proposed work is carried out in two steps; first a UWB monopole antenna is designed with simple half circular metallic patch and then a compact FSS reflector is realized using interdigital coupled resonator to enhance the antenna performance over the wide band.

\section{A) Antenna Design \& Results}

The UWB antenna can be simply realized by monopole circular disc patch. The motivation of the proposed antenna comes from this but with half circular disc for compact design. The proposed antenna in Fig. 1 is fabricated with a substrate of permittivity 3.2, loss tangent 0.003 and height of $1.6 \mathrm{~mm}$. The ground layer at the back plane is truncated around the feed for impedance matching purpose. Figure 2 depicts the reflection coefficient below $-10 \mathrm{~dB}$ is from $2.37 \mathrm{GHz}$ to $10.80 \mathrm{GHz}$ with fractional bandwidth of $129 \%$ and hence a good impedance matching over the wideband is achieved.

\section{B) FSS Design \& Results}

The proposed FSS comprises periodic array of unit cell elements having periodicity of $6 \mathrm{~mm} \times 6 \mathrm{~mm}$ in the vertical and horizontal direction. The top metallic layer is a compact interdigital coupled resonator printed on a dielectric substrate of permittivity 4.4 , loss tangent 0.02 and height of $0.5 \mathrm{~mm}$ as given in Fig. 3 (a).

The magnitude and phase plot of the FSS (in Fig. 3(b)) depicts that it has linear phase response over the antenna operating frequencies and the reflection coefficient is also maximum. Thus, it is well suited as a reflector for the gain enhancement of the antenna.

\section{C) FSS Reflector with Antenna}

The FSS reflector with size equal to the antenna is obtained by constituting $6 \times 6$ array of unit cell elements and placed beneath the antenna at a distance $h$ from the substrate and given in Fig. 4. Antenna gain can be enhanced when the EM wave radiated by the antenna and the reflected wave from the FSS are in phase at the antenna interface. Therefore, the following formulae must be satisfied [11].

$\emptyset_{-} f s s-2 \beta h=2 n \pi, n=-\infty$ to $+\infty$ 
Where, $\phi_{-}$fss is the FSS reflection phase; $\beta$ is the free space propagation constant. The airgap $h$ is calculated as $12 \mathrm{~mm}$.

Fig. 5 shows the fabricated prototype of the proposed design and its experimental validation is done by comparing with simulated one (in Fig.6). The measured $-10 \mathrm{~dB}$ reflection coefficient bandwidth for the ref. and proposed design are $92.80 \%$ and $84.74 \%$, respectively. The measured reflection coefficient patterns are closely following the simulated one except extra losses are added due to fabrication. A maximum gain enhancement of $4.25 \mathrm{dBi}$ is obtained with the FSS reflector when placed below the antenna at a distance of $12 \mathrm{~mm}$ and given in Fig. 7 .

The parametric studies on height (h) on the reflection and gain of the proposed antenna is given in Fig. 8 and Fig. 9, respectively. The result shows that with an increase in $h$, the return loss performance is improved due to loading effect. Whereas the gain performance decreases with increase in $\mathrm{h}$ due to magnitude of reflected signal inversely proportional with the distance between the antenna and reflector.

Figure 9 illustrates the radiation patterns of the antenna (ref.) and antenna with FSS (prop.) structures on the two orthogonal planes $(E$ and $H)$. The results clearly demonstrate the improvement with loading of FSS reflector to the antenna. The improvement in gain in the main lobe with narrow bandwidth and reduction of back-lobe levels is due to the addition of FSS reflector.

The main parameters of the proposed structure are compared with existing reported designs and tabulated in Table 1 below. In [12], a UWB FSS reflector with unit cell dimension of $13.5 \times 13.5 \mathrm{~mm}^{2}$ is proposed to obtain a maximum gain enhancement of $4.5 \mathrm{dBi}$ over the band. But the structure suffers from larger size of $115 \times 115 \mathrm{~mm}^{2}$. A relatively lesser structure dimension with $3.5 \mathrm{dBi}$ gain enhancement is achieved in [13]. In [14], a compact FSS with unit cell dimension of $11 \times 11 \mathrm{~mm}^{2}$ is able enhance the antenna gain over UWB range. A more compact FSS structure is reported in [15] but with larger structure and lesser gain. The proposed work is much compact as compared to others and also have good performances.

Table 1

Comparison Table

\begin{tabular}{|lllll|}
\hline Ref. & $\begin{array}{l}\text { Structure dimensions } \\
\left(\mathbf{m m}^{2}\right)\end{array}$ & $\begin{array}{l}\text { FSS unit cell size } \\
\left(\mathrm{mm}^{2}\right)\end{array}$ & $\begin{array}{l}\text { Bandwidth } \\
(\mathrm{GHz})\end{array}$ & $\begin{array}{l}\text { Max gain enhanced } \\
(\mathbf{d B i})\end{array}$ \\
\hline$[12]$ & $115 \times 115$ & $13.5 \times 13.5$ & $3.0-11$ & 4.5 \\
\hline$[13]$ & $84 \times 84$ & $14 \times 14$ & $4.7-14.9$ & 3.5 \\
\hline$[14]$ & $33 \times 33$ & $11 \times 11$ & $3.8-10.6$ & 3.5 \\
\hline$[15]$ & $82.5 \times 82.5$ & $8.25 \times 8.25$ & $2.5-11.0$ & 3.0 \\
\hline $\begin{array}{l}\text { This } \\
\text { work }\end{array}$ & $36 \times 36$ & $6 \times 6$ & $2.5-10.8$ & 4.25 \\
\hline
\end{tabular}




\section{lii. Conclusion}

A compact FSS reflector is proposed for gain enhancement of UWB antennas. The design topology is based on interdigital coupled resonator for miniaturized structure. The structure is able to give maximum gain enhancement of $4.25 \mathrm{dBi}$ over the UWB frequency when placed below a half circular disc radiator. The radiation results clearly demonstrate improvement in gain in the main lobe with narrow bandwidth and reduction of back-lobe levels is due to the addition of FSS reflector. The experimental results validate the design performance over the UWB frequency. This FSS reflector can be applied to any other antennas with some optimization in the design parameters and hence proves novelty of the structure.

\section{Declarations}

- Funding: None

- Conflicts of interest/Competing interests: None

- Availability of data and material (data transparency): Not Applicable

- Code availability (software application or custom code): Not Applicable

\section{References}

1. First Report and Order: Revision of part 15 of the commission's rules regarding ultra-wideband transmission systems, FCC 02-48, February 2002.

2. Joozdani, Z.; Amirhosseini, K.; Abdolali, A.: Wideband radar cross-section reduction of patch array antenna with miniaturized hexagonal loop frequency selective surface, Electron. Lett., 2016, 52, (9), pp. 767-768.

3. Akbari, M.; Ali, M., Sebak; M., et al.: Spatially mutual coupling reduction between CP-MIMO antennas using FSS superstrate, Electron. Lett., 2017, 53, (8), pp. 516-518.

4. Lazaro, A.; Ramos, A.; Girbau, D., et al.: A novel UWBRFID tag using active frequency selective surface, IEEE Trans. Antennas Propag., 2013, 61, (3), p. 1155-1168.

5. Oli, T.: Design of a star shaped high gain UWB antena using FSS for wireless communications, Microwaves RF, June 2014, pp. 83-92.

6. Ranga, Y.; Matekovits, L.; Weily, R.; et al.: A constnt gain ultra-wide band antenna with a multi-layer frequency selective surface, Prog. Electromagn. Res. Lett., 2013, 38, pp. 119-125.

7. Gobinda Sen; A. Banerjee; M. Kumar and S. Das: An Ultra-Wideband Monopole Antenna with a Gain Enhanced Performance Using a Novel Split-Ring Meta-Surface Reflector, Microwave and Optical Technology Letters, Vol. 59, pp. 1296-1300, 2017.

8. Krishna, S.; Kumar, R.: Slotted ground microstrip antenna with FSS reflector for high-gain horizontal polarisation, Electron. Lett., 2015, 51, (8), pp. 599-600.

9. Kundu, S., Chatterjee; A., Jana; S.K., et al.: A compact umbrella-shaped UWB antenna with gain augmentation using frequency selective surface, Radio Eng., 2018, 27, (2), pp. 448-454. 
10. Yahya, R.; Nakamura; A., Itami, M.: Design of constant gain UWB planar antenna using FSS-based reflectors, IEICE ComEx, 2016, 5, (1), pp. 27-32.

11. Yahya, R.; Itami, M.: Design of constant gain UWB planar antenna using single-layer FSS. IEEE Int. Symp. Antennas and Propagation USNC/URSI National Radio Science Meeting, Vancouver, BC, Canada, 2015, pp. 2015-2016.

12. Yahya, R.; Nakamura A.; Itami M., et al.: A novel UWB FSS-based polarization diversity antenna, IEEE Antennas Wirel. Propag. Lett., 2017, 16, pp. 2525-2528.

13. Das P; Mandal K.: Modelling of ultra-wide stop-band frequency-selective surface to enhance the gain of a UWB antenna, IET Microw Antennas Propag. 2019;13(3):269-277.

14. Abdulhasan RA; Alias R; Ramli KN; Seman FC; Abd-Alhameed RA.: High gain CPW-fed UWB planar monopole antenna-based compact uniplanar frequency selective surface for microwave imaging, Int J RF Microw Comput Aided Eng., 2019;29(8) : e21757.

15. Yanning Yuan; Xiaoli Xi; Yuchen Zhao: Compact UWB FSS reflector for antenna gain enhancement, IET Microw. Antennas Propag., 2019, Vol. 13 Iss. 10, pp. 1749-1755.

\section{Figures}

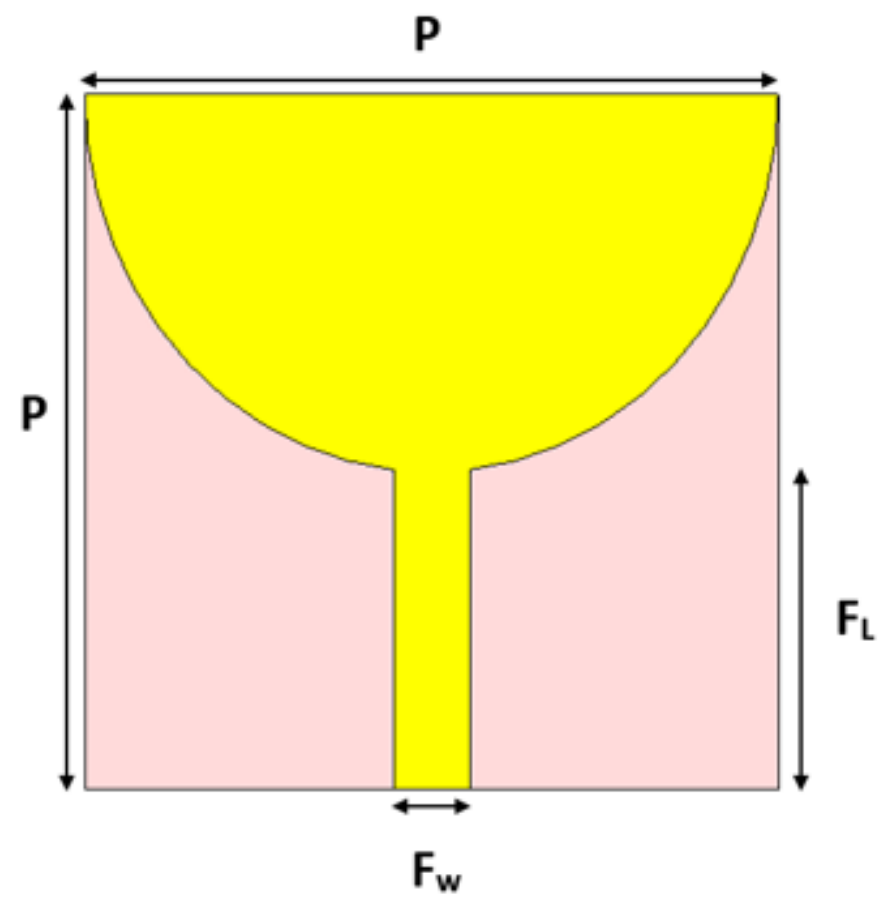

(a)

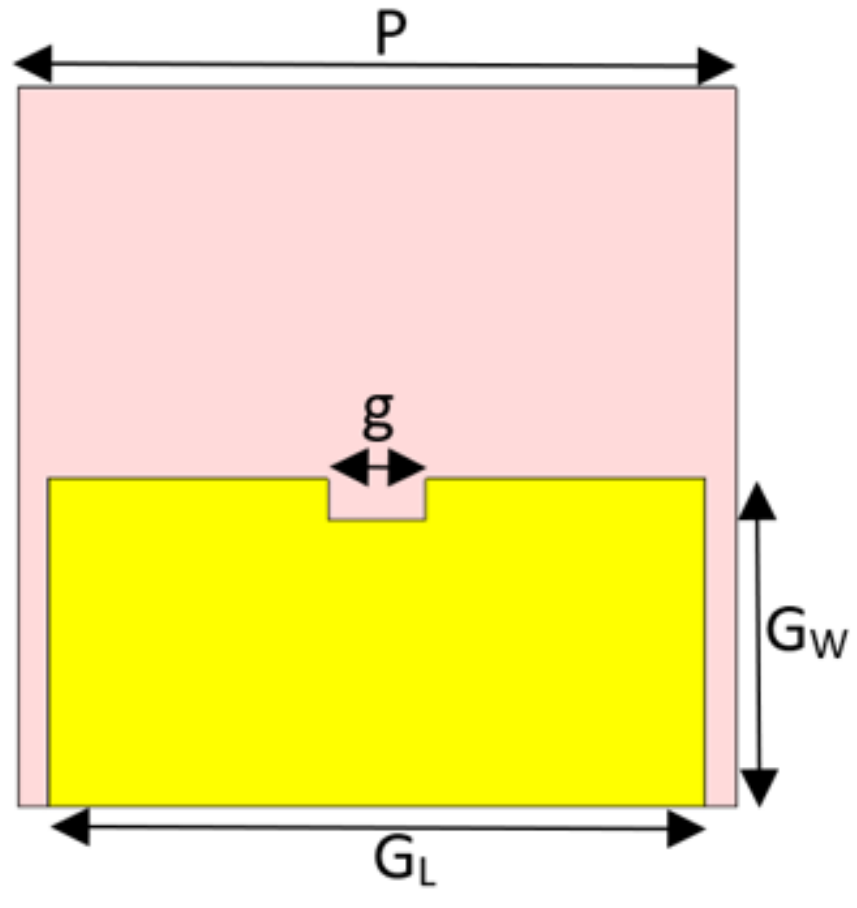

(b)

\section{Figure 1}

Proposed UWB antenna; (a) Top plane, (b) Bottom Plane (Physical Dimension (in ' $m$ m'): $P=35, F w=3.84$, $\mathrm{FL}=16.11, \mathrm{~g}=4.80, \mathrm{GL}=32, \mathrm{Gw}=16$ ) 


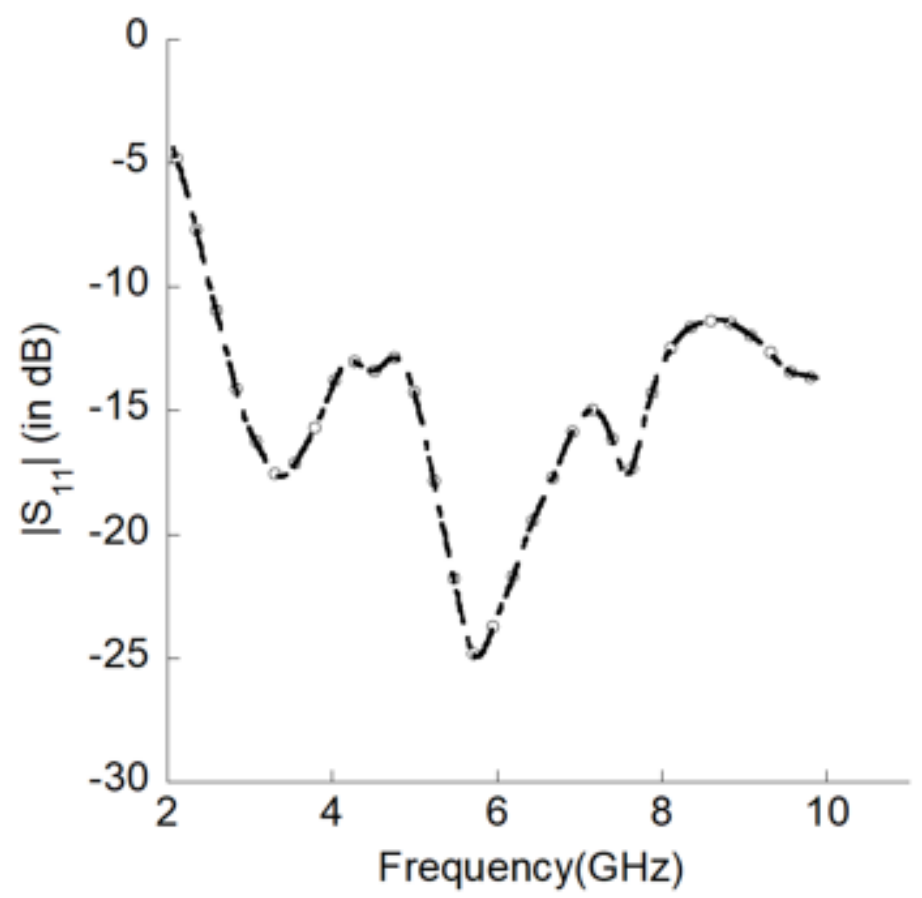

Figure 2

Proposed antenna reflection response

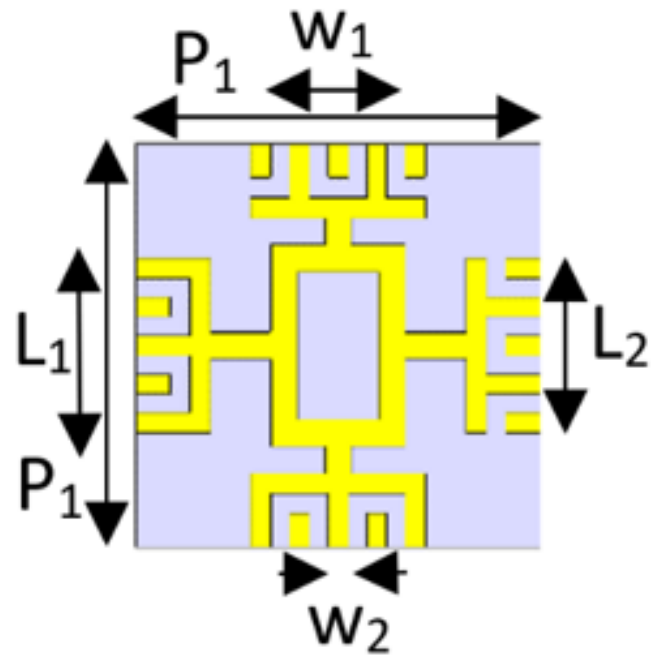

(a)

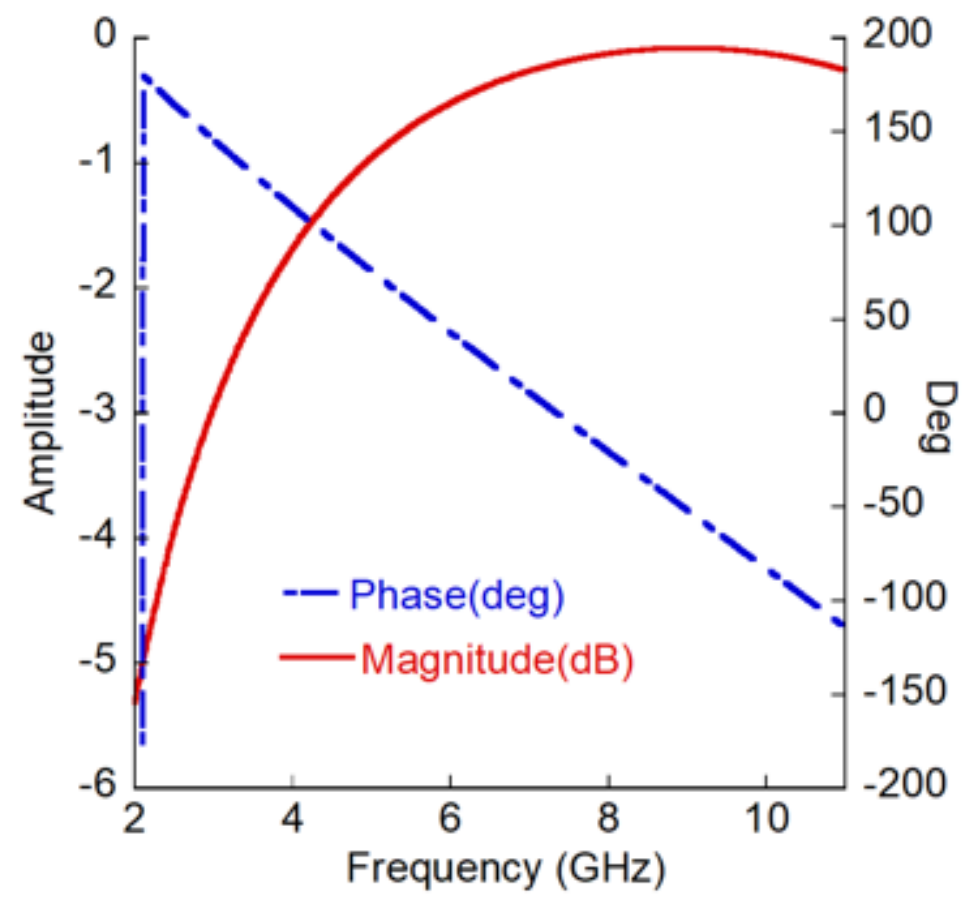

(b)

Figure 3

Proposed FSS reflector; (a) Unit cell, (b) Magnitude and phase response (Physical Dimension (in ' $m$ m'): $\mathrm{P} 1=6, \mathrm{~W} 1=2, \mathrm{~W} 2=0.3, \mathrm{~L} 1=3, \mathrm{~L} 2=2.6$ ) 


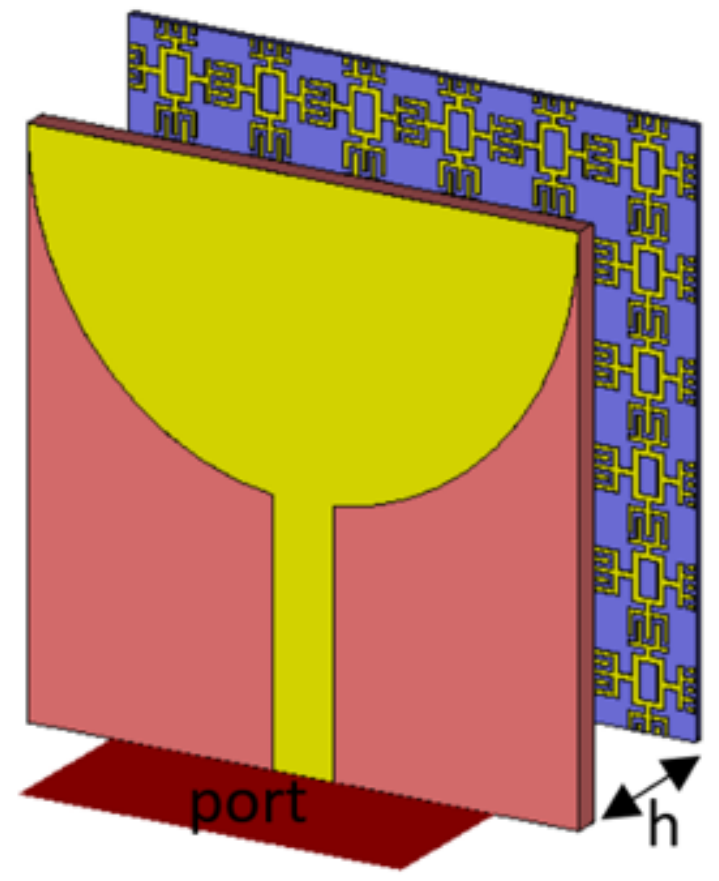

Figure 4

Proposed antenna reflection response 


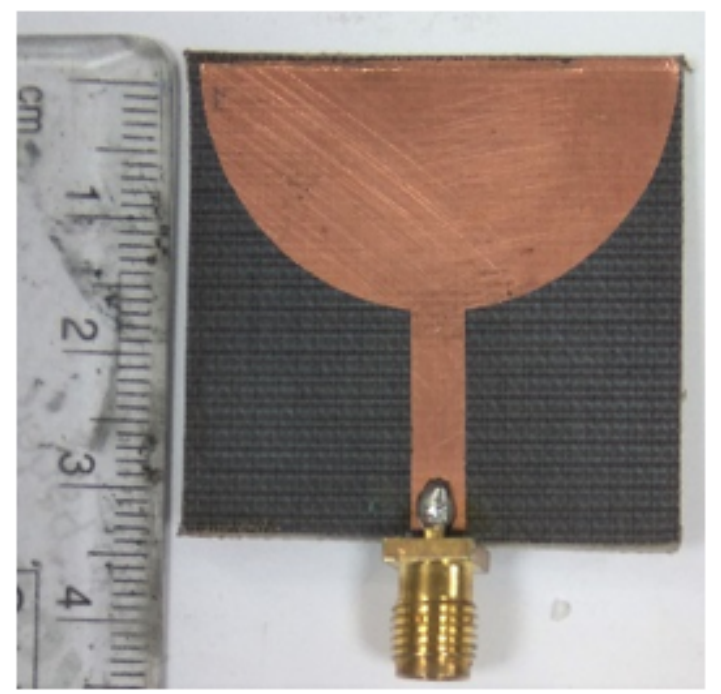

(a)

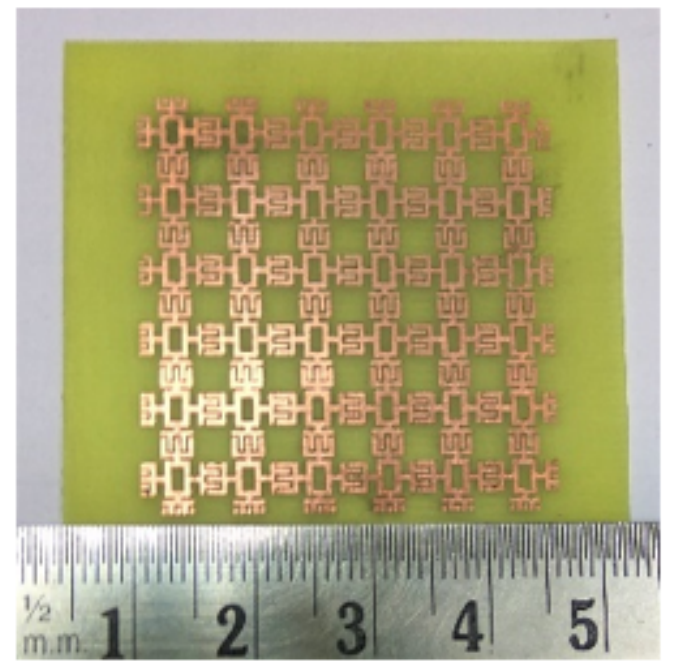

(c)

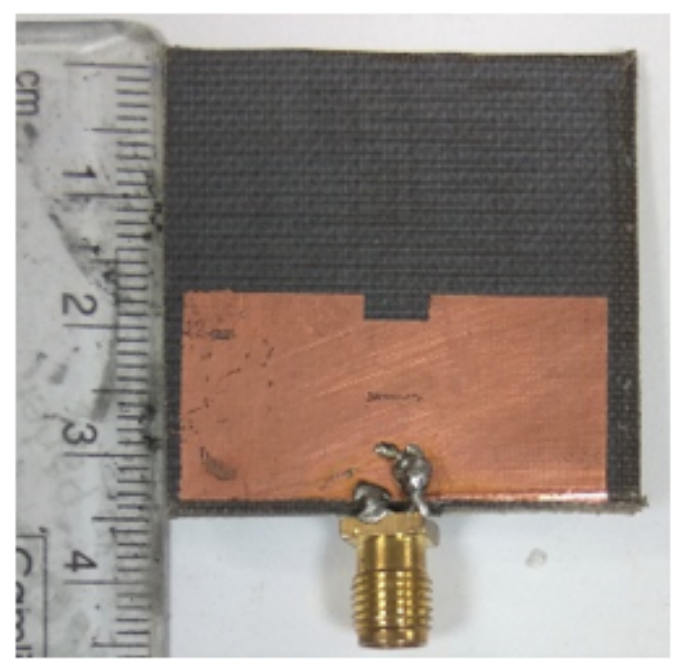

(b)

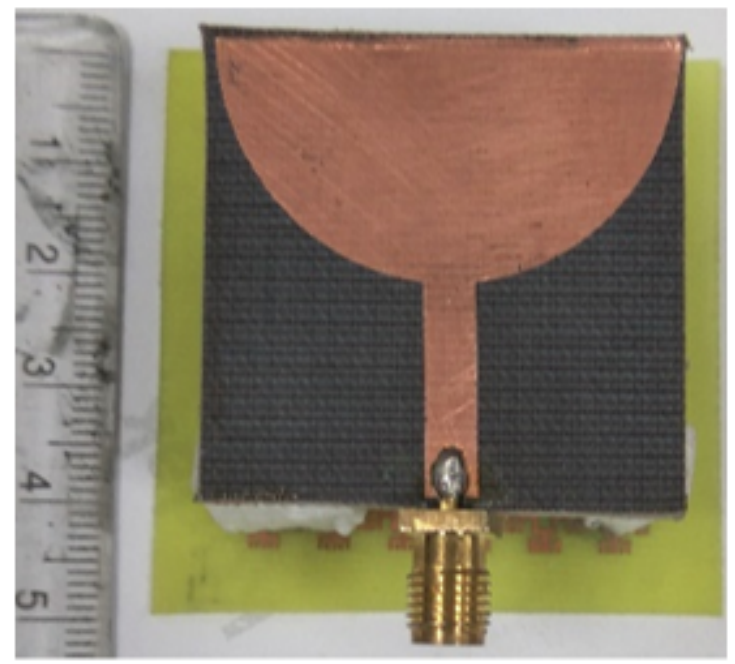

(d)

\section{Figure 5}

Fabricated prototypes: (a) Top plane of antenna, (b) Ground plane of antenna, (c) FSS, (d) Proposed antenna with FSS 


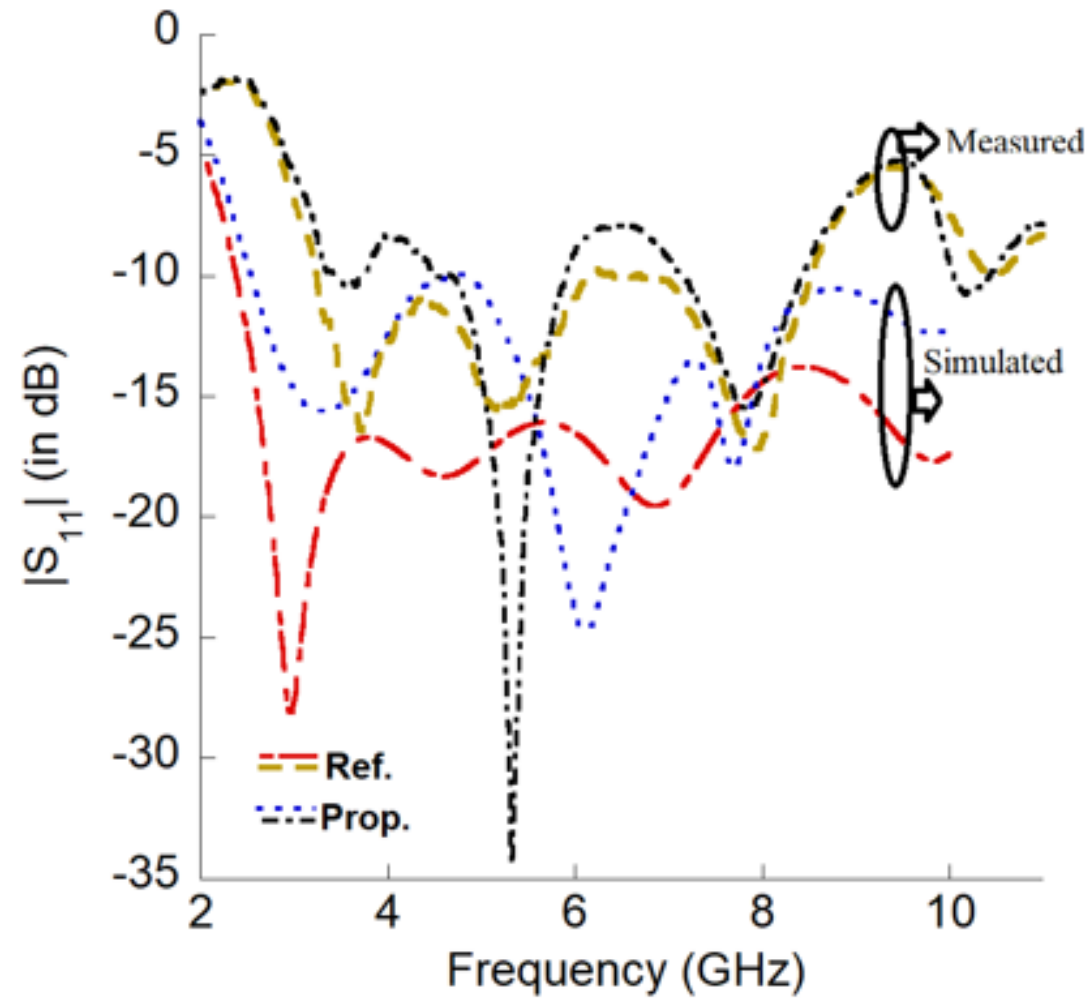

Figure 6

Simulated and measured results

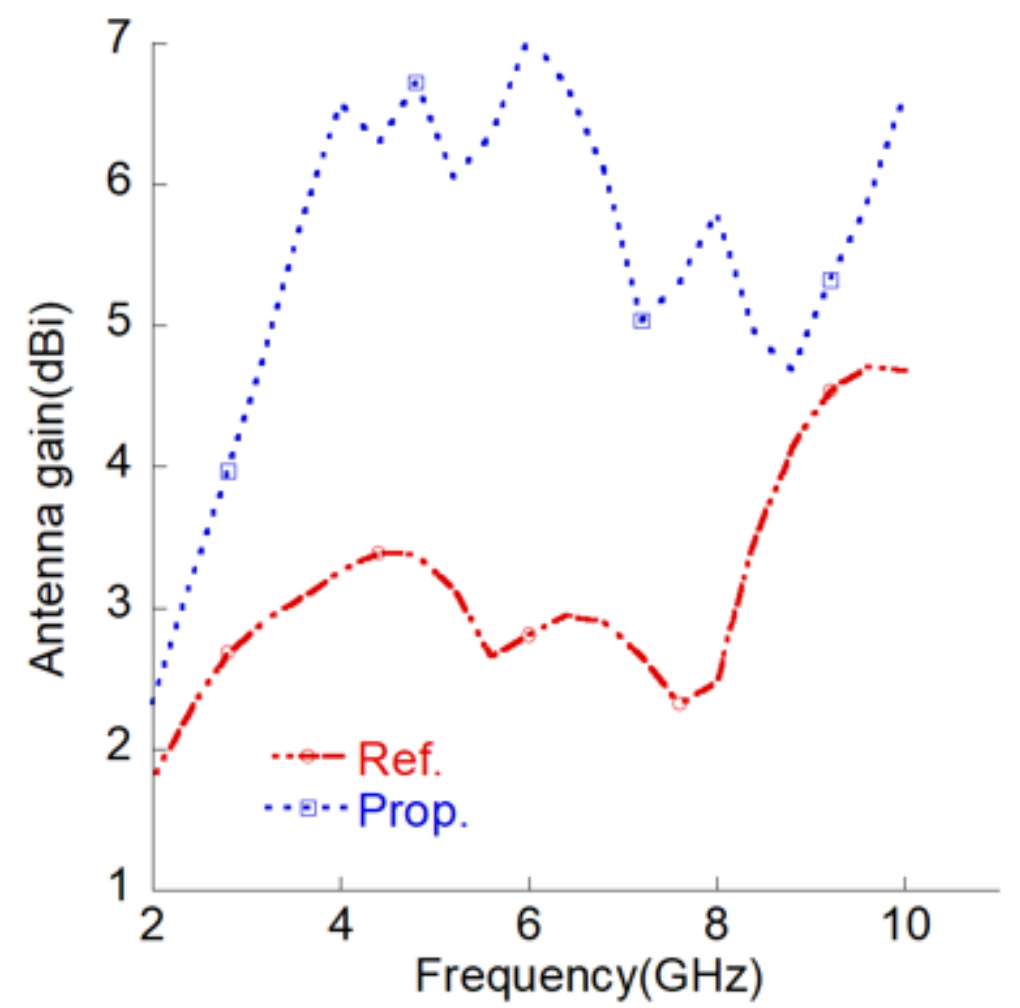

Figure 7 


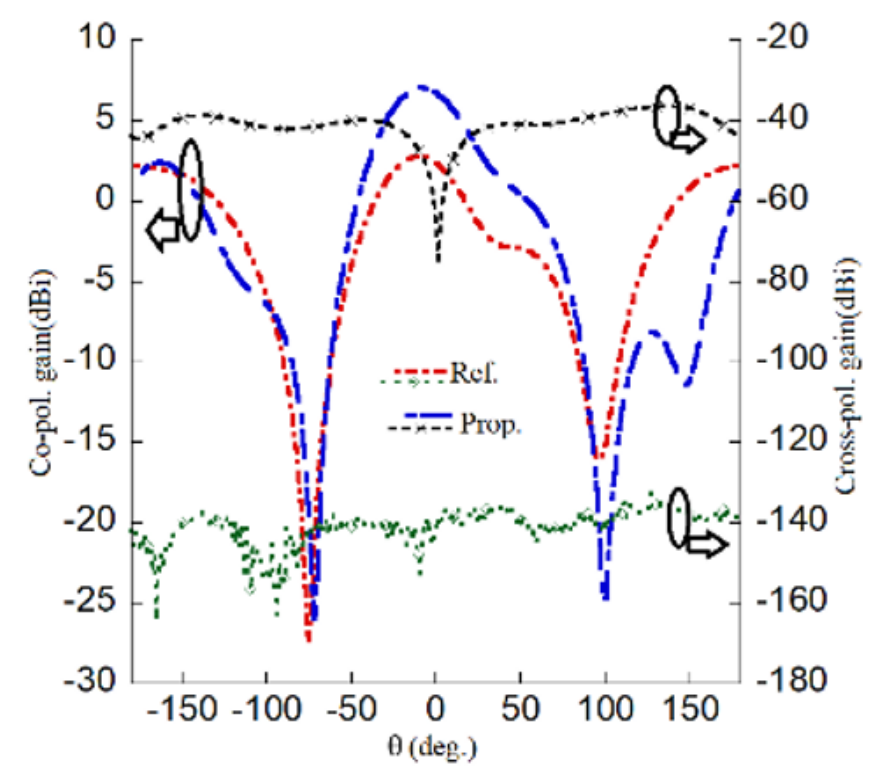

(a)

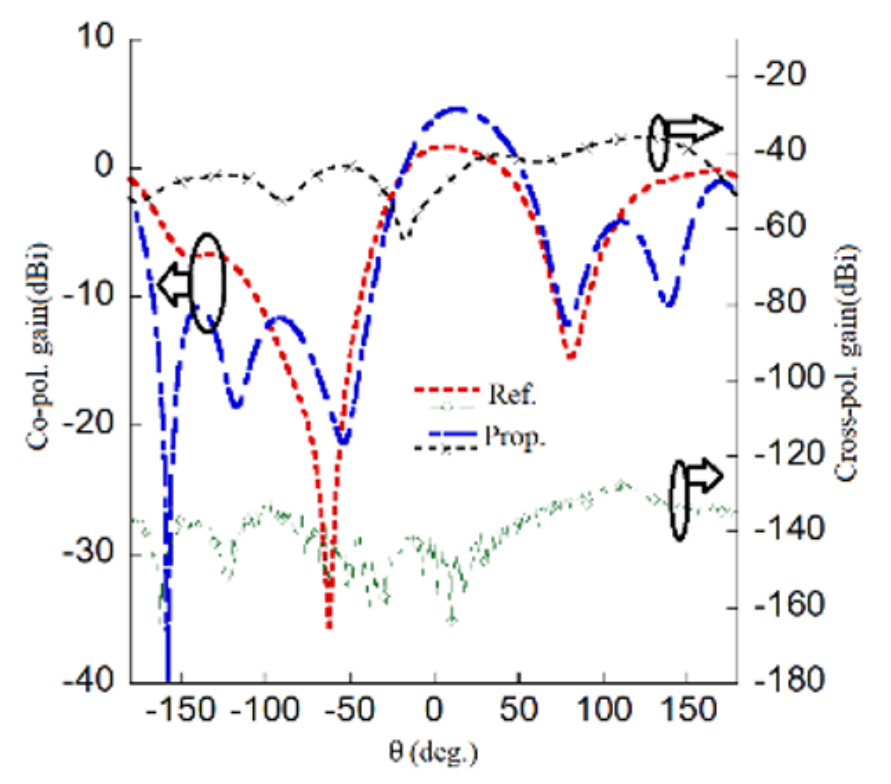

(c)

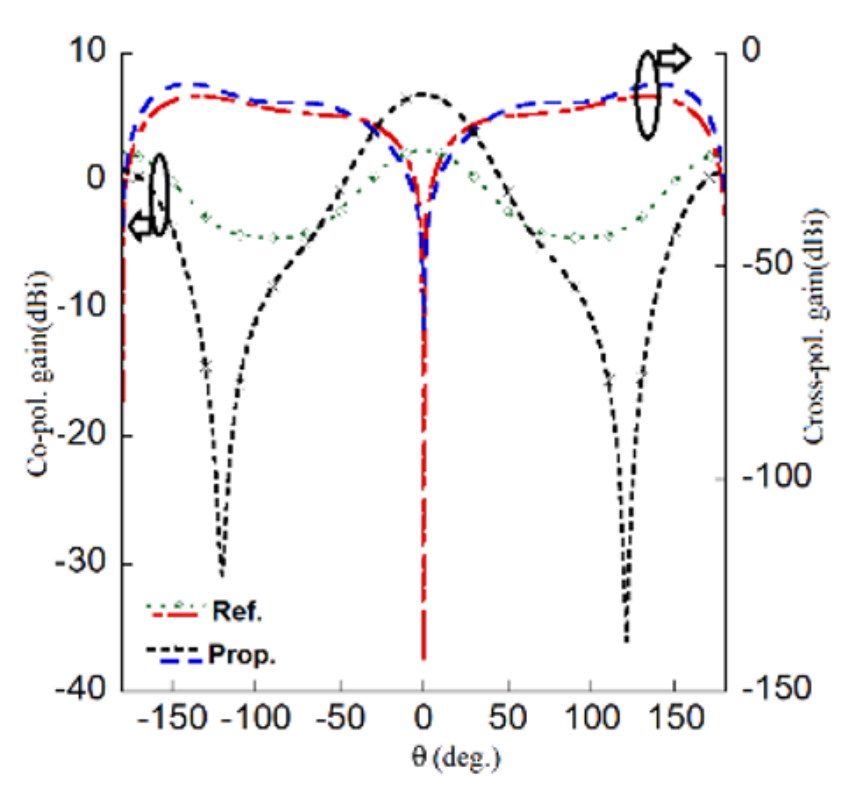

(b)

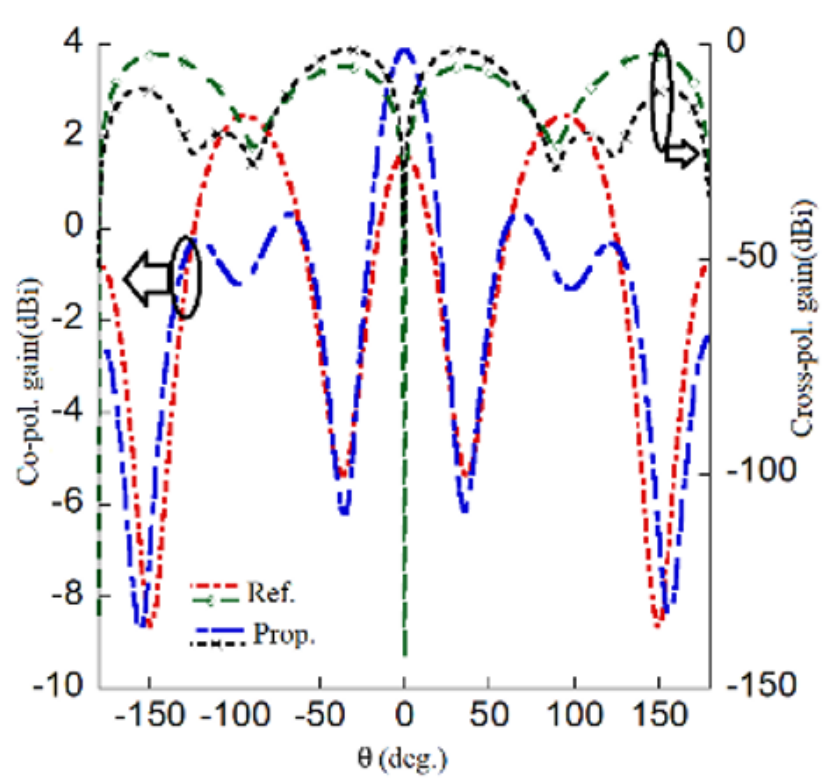

(d)

\section{Figure 8}

Radiation patterns of the Ref. (antenna) and Prop. (antenna with FSS): (a) E-plane, (b) H-plane - $6 \mathrm{GHz}$, (b) E-plane, (c) H-plane - $8 \mathrm{GHz}$, 